\title{
Epistemologías, oligarquías y escrituras en crisis. Del racialismo al culturalismo en el ensayo latinoamericano de los años treinta
}

\author{
Alejandra Mailhe
}

Universidad Nacional de la Plata-CONICET

Este trabajo comparativo analiza los ensayos producidos en Brasil y en el Caribe en torno a los años treinta, centrándose en las operaciones llevadas a cabo por los intelectuales para apropiarse de las culturas populares. Considera tres textos relevantes y casi no explorados en términos comparativos: Ainsi parla l'oncle del haitiano Jean Price-Mars (1928), Casa-grande e senzala del brasileño Gilberto Freyre (1933), y Contrapunteo cubano del tabaco y el azúcar del cubano Fernando Ortiz (1940). En particular, esos discursos son analizados a partir de las nuevas significaciones asignadas a la herencia afroamericana y de las interacciones que establecen con la vanguardia estética, para romper en conjunto con los determinismos heredados de la etapa anterior.

PALABRAS CLAVE: intelectuales, cultura popular, ensayismo brasileño, ensayismo caribeño, años treinta.

This comparative paper analyzes Brazilian and Caribbean essays in the thirties, focussed on the operations made by the intellectuals to appropriate the popular cultures. It studies three texts, relevant and nearly unexplored in comparative terms: Ainsi parla l'oncle of Haitian Jean Price-Mars (1928), Casa-grande e senzala of Brazilian Gilberto Freyre (1933), and Contrapunteo cubano del tabaco y el azúcar of Cuban Fernando Ortiz (1940). Specifically, these discourses are analyzed from the new meanings given to the AfroAmerican heritage and from the interactions they establish with the aesthetic vanguard, to break as a whole with the determinants inherited from the previous stage.

KEYwords: intellectuals, popular culture, Brazilian essays, Caribbean essays, thirties.

¿Cuál es el alcance del "resquebrajamiento" del paradigma racialista en los ensayos latinoamericanos enunciados en torno a los años treinta? En particular en contextos nacionales como los de Brasil, Cuba y Haití, ¿qué nuevas semantizaciones operan sobre la herencia afroamericana? ¿Qué interacciones establecen estos textos con la vanguardia estética, en la desarticulación de los determinismos heredados de la etapa anterior? Y finalmente, ¿qué modulaciones adquiere la ideología del mestizaje racial y de la 
transculturación en cada uno de esos contextos socioculturales y políticos diversos? Este trabajo indaga en torno a estos interrogantes, comparando tres ensayos relevantes y casi no explorados en términos comparativos: Ainsi parla l'oncle del haitiano Jean Price-Mars, de 1928, Casa-grande e senzala del brasileño Gilberto Freyre, de 1933, y Contrapunteo cubano del tabaco y el azúcar del cubano Fernando Ortiz, de 1940. En especial, atendemos aquí a las miradas emergentes sobre la cultura popular que entablan un diálogo tenso (y a menudo saturado de contradicciones) entre sí y con las huellas todavía activas de los ideologemas residuales heredados del siglo XIX.

Antes de abordar comparativamente los textos, creemos importante realizar dos aclaraciones. Por un lado, que este trabajo forma parte de una investigación mayor (recientemente iniciada) que se propone analizar comparativamente la mirada antropológica y literaria que los intelectuales de Brasil, Cuba y Haití despliegan en los años treinta sobre las culturas populares. Por otro lado, que esta comparación tiene en cuenta la existencia tanto de sólidos puntos de contacto como de diferencias significativas (económicas, sociales, históricas, políticas) entre estos tres países, y especialmente entre las producciones culturales de la etapa a considerar. Lejos de impugnar la operación comparativa, el juego entre convergencias y divergencias en la historia y en la coyuntura crítica de los años treinta pueden enriquecer el resultado de esta puesta en diálogo.

Entre otros rasgos comunes, las tres áreas son el resultado de largos procesos históricos semejantes, que involucran conquista y exterminio de las poblaciones autóctonas, la instauración de economías de plantación, la explotación esclavista y la emergencia de conflictos socioculturales semejantes derivados de la esclavitud, que convierten estas áreas en paradigmas culturales de las "Américas negras". Al mismo tiempo, entre las numerosas diferencias, la colonización parece haber generado sistemas de cohesión social mucho más fuertes en el contexto brasileño y cubano que en el de Haití. En los países caribeños, la gravitación del imperialismo norteamericano es evidentemente mayor, agravándose en las primeras décadas del siglo $\mathrm{XX}$, con inflexiones diversas en cada caso (más indirectamente en el caso de Cuba, en donde los Estados Unidos controlan progresivamente la economía y la política, vulnerando la soberanía nacional, y más abiertamente en el caso de Haití, ocupado por los Estados Unidos entre 1915 y 1934. Frente a la relativa homogeneidad nacional sostenida en Brasil (a pesar de los diversos conflictos regionalistas), los pequeños países del Caribe se inscriben en un contexto político y cultural marcado por la fragmentación "antillana" y la 
convivencia conflictiva de lenguas y culturas heterogéneas, producto de colonizaciones diversas y aluviones inmigratorios desiguales. ${ }^{1}$ A la vez, en el siglo XIX los tres países atraviesan procesos independentistas heterogéneos y cronológicamente muy asimétircos. A fines del siglo XIX, aunque experimentan grados de modernización económica y social muy desiguales, en los tres casos la consolidación del orden neocolonial implica un fuerte debilitamiento de las antiguas clases altas terratenientes, un proceso común que tendrá consecuencias directas en la crisis posterior del treinta. ${ }^{2}$

A pesar de estas diferencias, desde la colonia hasta fines del siglo XIX las elites intelectuales forjan linajes representacionales marcadamente etnocéntricos para aprehender lo popular. Las sucesivas reformulaciones de la razón racial (desde las jerarquizaciones coloniales y románticas hasta el racialismo científico de entresiglos) convergen en conceptualizar el elemento afro como un "escollo" particularmente significativo para la consolidación de una "civilización moderna". El mismo linaje devaluador gravita en torno a las connotaciones asignadas al trópico como espacio simbólico común, resistente "por antonomasia" al racionalismo y la productividad eurocéntricos. ${ }^{3} \mathrm{Al}$ mismo tiempo, las elites forjan imágenes del otro como modelos sobre los cuales se recorta la propia identidad (en el siglo XIX, el ejemplo haitiano de rebelión negra gravita negativamente en los otros sistemas esclavistas, al tiempo que en los años veinte se registra en la elite cubana -incluso entre los intelectuales de vanguardia — un temor sostenido a la "africanización de Cuba" por la migración de haitianos).

Este tipo de representaciones relativamente convergentes consolidan un background simbólico compartido para abordar la otredad sociocultural. Frente a éste se reposicionarán insistentemente los intelectuales de los años treinta, generando sus propios linajes genealógicos y sus fracturas radica-

1 Véanse Glissant, Édouard: Le discours antillais, Seuil, Paris, 1981; Introduction a une poétique du divers, Galimard, Paris, 1996; y también Pizarro, Ana : "La noción de literatura latinoamericana y del Caribe como problema historiográfico", en Pizarro, Ana (coord.): La literatura latinoamericana como proceso, CEAL, Buenos Aires, 1985 entre otros. La gravitación del imperialismo norteamericano, muy desigual entre Brasil y los países del Caribe (más expuestos al intervencionismo directo), también debe considerarse como un factor diferenciador significativo y con consecuencias indirectas en el campo cultural. Madrid, 1985

2 Véase Halperín Donghi, Tulio: Historia contemporánea de América Latina, Alianza,

3 Véanse Gerbi, Antonello: La naturaleza de las Indias Nuevas, FCE, México, 1993; La disputa del Nuevo Mundo, FCE, México, 1995; Todorov, Tzvetan: Nosotros y los otros, Siglo XXI, México, 1991; Skidmore, Thomas: Preto no branco. Raça e nacionalidade no pensamento brasileiro, Paz e Terra, San Pablo, 1989; y Hurbon, Laënnec: El bárbaro imaginario, FCE, México, 1993. 
les con el pasado, como condición sine qua non para iniciar una puesta en crisis del paradigma racialista y un giro hacia la interpretación cultural.

Además de los trazos generales de convergencia y dispersión entre estas áreas, el elemento que parece sesgar la enunciación de estos ensayos (aunque de manera mediada y con variables significativas en cada caso) son las crisis económicas, sociales, políticas y culturales que sacuden a América Latina, en el marco de la más amplia crisis del capitalismo mundial desatada en $1929 .{ }^{4}$ En cada campo nacional esas crisis presentan inflexiones particulares.

A lo largo de la década del veinte Brasil experimenta una serie de transformaciones políticas e ideológicas significativas, en el marco de las cuales se debilita la hegemonía de la República oligárquica. ${ }^{5}$ En el período aumenta la significación política de las masas, al tiempo que se produce un fuerte recrudecimiento de las ideologías (acentuado hacia la década del treinta), en cuyo contexto se institucionalizan la izquierda y la derecha a nivel nacional. También en el campo de la cultura se producen, en la década del veinte, transformaciones profundas que radicalizan la experiencia de la modernidad y suscitan una progresiva puesta en cuestión de los discursos sociales hasta entonces hegemónicos. En este contexto emerge la vanguardia estética del modernismo, que altera los cánones estéticos hasta entonces vigentes, ${ }^{6}$ a la vez que emprende una crítica global al discurso artístico heredado y al contexto cultural, ideológico y político, expresando en el nivel estético-cultural los conflictos ideológicos que preceden a las transformaciones estructurales de los años treinta. Influido por la apelación a las culturas primitivas llevada a cabo por las vanguardias europeas, el modernismo brasileño (y especialmente la obra de Mário de Andrade) se orienta enfáticamente hacia las culturas populares, inscribiendo elementos provenientes de ellas en las obras de la alta cultura. De manera convergente, el ensayismo

4 En términos generales (y sin obviar las diferencias evidentes entre casos tan dispares como los de Brasil y Haití), puede afirmarse que la crisis latinoamericana de 1930 puede pensarse como una "crisis orgánica", en la medida en que entra en crisis la dominación oligárquica heredada de la década del ochenta y emergen nuevos actores sociales hasta entonces ajenos al poder. Esa crisis múltiple repercute y se procesa en el campo cultural. Sobre la caracterización del contexto latinoamericano de los años treinta como de "crisis orgánica" véase Ansaldi, Waldo, (ed.): Tierra en llamas. América Latina en los años 1930, Al Margen, La Plata, 2000, págs. 13-46.

5 Entre las principales transformaciones que irán acercando a esa derrota política, los levantamientos "tenentistas" en favor de la "republicanización de la República" conducen hacia la "Revolución" de Getúlio Vargas en 1930, dándose así clausura a la "República Velha".

6 Para considerar el lazo entre el modernismo brasileño y el resto de las vanguardias latinoamericanas, véase Schwartz, Jorge: Las vanguardias latinoamericanas. Textos programáticos y críticos, Cátedra, Madrid, 1991, entre otros. 
de Freyre focaliza insistentemente el problema de la heterogeneidad racial/cultural y la definición del carácter nacional, retomando así discusiones heredadas, para evaluar positivamente los efectos de la "miscigenação". Al menos en parte, su discurso constituye un emergente del pensamiento de la oligarquía nordestina, desplazada de su antiguo rol hegemónico nacional, y en busca de estrategias de reivindicación de su papel dominante. ${ }^{7}$ Por ello, en el comportamiento intelectual de Freyre se percibe cierto sentido de mando, marcas de distinción y de prestigio y una visión señorial del mundo, capaz de convertir la ideología de su estamento dominante en explicación de toda la historia nacional, aunque - como veremos - adopte también una mirada crítica respecto de la ideología de las clases dirigentes, especialmente para pensar la cultura popular. En ese sentido, ante una crisis oligárquica de larga duración que se acelera con la implantación del nuevo capitalismo, su obra profundiza - y al mismo tiempo resiste - el colapso de la Primera República y, con ella, del orden señorial.

En el caso de Cuba, la decadencia de la aristocracia hacendada cubana en las primeras décadas del siglo XX acelera la penetración económica y el intervencionismo político de los Estados Unidos. Estos acontecimientos contribuyen a la emergencia de una conciencia nacional por parte de la elite intelectual en las primeras décadas del siglo XX, aunque ese incipiente nacionalismo sea minado por la - sutil o explícita- penetración de los Estados Unidos y por el apoyo a éste por parte de la elite que controla la economía cubana. ${ }^{8}$

7 Gilberto Freyre (1900-1975) pertenece a una familia tradicional de hacendados nordestinos. Recibe una educación elevada (de orientación protestante), que incluye varios viajes iniciáticos a Estados Unidos y Europa (que le permiten graduarse como Master en Ciencias Políticas en la Universidad de Columbia, y entrar en contacto con teorías sociales más modernas, como la antropología culturalista de Franz Boas). Regresa a su Recife natal en 1923, percibiendo el Brasil popular desde una posición ambivalente, entre la distancia sociocultural y la fascinación y pertenencia. En 1926 asume un primer cargo político importante, como jefe de gabinete del gobierno de Pernambuco. Cuando estalla la revolución de 1930, se exilia en Lisboa y luego se traslada a Standford como profesor visitante, reuniendo material para la escritura de su futuro ensayo Casa-grande... En 1931 regresa a Brasil para concluir ese texto y publicarlo en 1933, suscitando una reacción inmediata de los sectores conservadores (que rechazan su negrofilia y la exaltación de la sensualidad). De la década del treinta en adelante, la relación de Freyre con el campo político y académico nacional será particularmente compleja. Por ejemplo, en este último campo, desde 1935 se desempeña como profesor de sociología en Recife, al tiempo que crece su reconocimiento a nivel internacional; pero en el campo nacional la validez sociológica de su producción es minada por la moderna sociología en ascenso (especialmente desde el foco de la USP), que pone en cuestión su autoridad científica. Al respecto, véase por ejemplo Mota, Carlos Guillherme : Ideologia da cultura brasileira (1933-1974), Atica, San Pablo, 1978, págs. 53-74.

8 Véase Moreno Fraginals, Manuel: "Economías y sociedades de plantaciones en el Caribe español. 1860-1930”, en Bethell, L. (comp.): Historia de América Latina, vol. 7, Crítica, Barcelona, 1991. 
Desde el punto de vista social, en las dos primeras décadas del siglo $\mathrm{XX}$ emergen nuevos movimientos políticos ${ }^{9} \mathrm{y}$ actores sociales que buscan oponerse a la hegemonía oligárquica; ${ }^{10}$ incluso en el interior de los sectores populares algunos grupos comienzan a organizarse como minorías étnicas. ${ }^{11}$ Frente al autoritarismo político de Machado, los textos producidos por numerosos intelectuales reformistas y nacionalistas reclaman la construcción de una república democrática. ${ }^{12}$ En este contexto crítico se producen ensayos paradigmáticos como los de Fernando Ortiz, y emergen las primeras manifestaciones de una estética vanguardista que, en algunos casos, realiza una incorporación legitimante de materiales culturales afrocubanos. Aunque ensayismo y vanguardia convergen al realizar un mismo diagnóstico doloroso sobre la crisis nacional, estos discursos aparecen saturados de puntos de conflicto, especialmente al evaluar los componentes y la importancia nacional de "lo popular". Aun en el seno de estas contradicciones, se produce un viraje conjunto en la definición de la cultura popular y de la identidad nacional. Este cambio es claramente legible en los propios textos de Fernando Ortiz, en su evolución desde principios del siglo XX hasta 1940. Como Freyre, también Ortiz proviene de una familia de la clase dirigente nacional, aunque con una orientación más bien burguesa y modernizadora; como Freyre, Ortiz despliega una intensa actividad política y académica (centrada en la emergente antropología nacional), adquiriendo así un lugar central en el seno del campo cultural, y alcanzando reconocimiento profesional dentro y fuera de su país. A diferencia de Freyre, desde sus primeras intervenciones intelectuales, Ortiz asume posiciones afines al

9 Como el Partido Comunista Cubano, fundado en 1925 por antiguos organizadores laboristas (como Carlos Baliño), líderes estudiantiles (como Julio A. Mella) y ex-anarquistas.

10 Así por ejemplo, en 1915 se celebra el primer congreso obrero en La Habana, que demuestra la fuerza incipiente de la clase trabajadora y la influencia del anarquismo (que había penetrado en la isla en el s. XIX por medio de las organizaciones de trabajadores del tabaco), pero que también deja al descubierto las enormes dificultades que enfrentan los trabajadores azucareros para organizarse. Véase Aguilar, Luis E: "Cuba, 1860-1934", en Bethell, Leslie (ed.), Historia de América Latina, vol. 9, Crítica, Barcelona, 1992, pág. 230.

11 En este contexto, en 1907 surge el "Partido Independiente de Color", que acusa a la república de traicionar a la población negra. Pretendiendo consolidarse como fuerza política, y encontrando la oposición de leyes nacionales — que prohíben los partidos políticos basados en la raza o en la religión-, este movimiento provoca una rebelión en 1912. La fuerte represión de este episodio por el gobierno nacional (en el marco de una nueva intervención norteamericana) deja una huella traumática, obstaculizando en los años siguientes la participación de los negros en la política cubana.

12 En los primeros años de la década del treinta emerge una nueva experiencia de lucha política en la que intervienen sectores enteros de la sociedad cubana (sobre todo los trabajadores y la elite intelectual) enfrentándose al gobierno, hasta provocar la caída de Machado en agosto de 1933 y el surgimiento de una breve e inédita experiencia revolucionaria en el poder. Véase Aguilar: Historia de... 
reformismo liberal. ${ }^{13}$ Partiendo, a principios de siglo, de un análisis positivista y etnocéntrico sobre la cultura popular (especialmente referido al margen negro), Ortiz desemboca en una revisión crítica del papel de la vieja oligarquía en la historia nacional, y en el análisis culturalista de los procesos de mestizaje en los que se forja "desde abajo" la identidad colectiva, cobrando un peso cada vez más significativo la experiencia colonial y la legitimación de los elementos afroamericanos.

Por su parte, Haití aparece sesgado, desde el comienzo de su temprana autonomía política, por profundas divisiones sociales entre la elite mulata y los sectores populares negros (en su mayoría campesinos pobres, descendientes de esclavos, dueños de minúsculas parcelas de tierra, analfabetos y débilmente aculturados dada la intervención tardía y frágil de la Iglesia). Pero a pesar de sus problemas políticos y económicos, y del carácter reducido de su elite, antes de la ocupación norteamericana en 1915 Haití presenta una rica vida intelectual. En este contexto, a fines del siglo XIX la incipiente antropología nacional se empeña en refutar los principales prejuicios del imaginario heredado para pensar el universo negro, postulando un primer programa de rehabilitación de estas culturas. ${ }^{14}$ Sin embargo, lo

13 Descendiente de un comerciante español y de madre cubana, Fernando Ortiz (1881-1969) estudia Derecho en Cuba y España, doctorándose allí en 1901 y dedicándose inicialmente a la criminología. Luego de un breve regreso a Cuba en 1902, vuelve a Europa como cónsul, y entra en contacto personal con figuras paradigmáticas del positivismo, como Lombroso y Ferre. A partir de 1906, cuando comienza a publicar su obra criminológica, sus actividades oficiales y académicas se multiplican: ejerce el derecho; enseña Ciencias Sociales y Derecho en la Universidad de La Habana; desde 1915 se vincula abiertamente al Partido Liberal; funda numerosas sociedades y organizaciones científicas cubanas e internacionales. Desde 1917 es representante de la Cámara por el Partido Liberal, pero en 1922 se aleja de la política al oponerse a la corrupción de la clase dirigente y al avance del imperialismo norteamericano, elementos clave que impiden plasmar sus aspiraciones reformistas. También en esta etapa se vincula con el grupo Minorista (integrado por Martínez Villena, Juan Marinello y Alejo Carpentier entre otros) y apoya los principios estéticos e ideológicos de la vanguardista revista de avance. Cuando en 1925 Machado se instala en el poder, Ortiz se exilia en los Estados Unidos, dedicándose a continuar sus investigaciones y a establecer lazos con intelectuales norteamericanos progresistas, críticos del imperialismo., Al caer la dictadura de Machado, regresa a Cuba en 1933 y retoma la actividad académica centrada en el estudio de la cultura nacional, para lo cual dirige publicaciones como la Revista Bimestre Cubana, y funda organismos como la Sociedad de Estudios Afrocubanos. Al respecto, véase por ejemplo Le Riverend, Julio : "Prólogo" y "Cronología" a Ortiz, Fernando, en Contrapunteo cubano del tabaco y el azúcar, Ayacucho, Caracas, 1978.

14 Los intelectuales de entresiglos enfrentan el desafío de realizar una primera desarticulación de ese imaginario estigmatizante, ya que en los discursos de las elites intelectuales de Europa y América Latina, desde la colonia hasta fines del s. XIX inclusive, Haití aparece recurrentemente sesgado por el atraso económico, el despotismo político y/o el predominio de supersticiones salvajes, convertido, entonces, en uno de los polos más "bárbaros" de un "continente bárbaro". Varios textos del ensayismo haitiano de entresiglos se centran en refutar el racialismo europeo y norteamericano, sosteniendo un elogio caluroso de la raza negra y colocando al propio Haití como prueba de la igualdad racial. Véase Hurbon, Laënnec: El bárbaro imaginario, FCE, México, 1993. 
hacen desde una perspectiva positivista y todavía etnocéntrica acorde con las conceptualizaciones de la alteridad hegemónicas en esta etapa, y confiando de manera implícita en el conocimiento de la cultura del "otro" como vía para asegurar una más eficaz europeización del país.

La ocupación produce un viraje significativo en el proceso social y cultural haitiano, formando parte de un plan general de los Estados Unidos para ejercer un control estratégico en el Caribe. Es inicialmente apoyada por la elite dirigente haitiana, que en general justifica el intervencionismo como vía para fomentar el desarrollo y/o controlar la agitación social. Pero con la oposición creciente de las masas y los sectores medios, crece también la resistencia activa, alcanzando un punto máximo en 1929, cuando se producen diversas protestas fuertemente reprimidas por el gobierno. ${ }^{15}$

El rechazo de la intervención se canaliza también a través del creciente movimiento nacionalista, al que se suman miembros de la elite antes partidarios de los Estados Unidos, creándose así una resistencia cohesionante entre sectores raciales y sociales diversos. ${ }^{16}$ Los movimientos etnológicos y literarios promovidos por la elite haitiana producen entonces un giro radical en el modo de pensar la identidad y alteridad nacionales. En efecto, bajo la influencia del marxismo y las vanguardias estéticas, emergen algunos discursos paradigmáticos que resisten el imperialismo norteamericano y, al mismo tiempo, cuestionan el racialismo, la herencia etnocéntrica y el colonialismo cultural en general. Así, la ocupación opera como un catalizador que impulsa el reconocimiento de la cultura popular: reaccionando frente al imperialismo, la elite intelectual (encabezada por figuras como Jean Price-Mars y Jacques Roumain, y nucleada en torno a la llamada "escuela indigenista") convierte la cultura negra en emblema de la identidad nacional, despojando sus prácticas de las connotaciones negativas heredadas de las etapas previas, aunque esta legitimación no implique todavía un abandono completo del paradigma racial. Así, la vanguardia y el ensayo de esta etapa (situados ambos bajo la figura paternal de Price-Mars) polemizan tanto con los discursos racistas embanderados por los partidarios de la ocupación como con las representaciones heredadas de entresiglos. En la década del treinta emergen algunas experiencias de vanguardia, buscando soluciones sincréticas propias a las tensiones radicales (socioculturales, históricas y lingüísticas) que sesgan el escenario

15 Véase Nicholls, David : "Haití, 1870-1930", en Bethell, Leslie (ed.): Historia de América Latina, vol.9, Crítica, Barcelona, 1992, págs. 275-289.

16 Véase Hurbon: El bárbaro... 
nacional. El noirisme inaugurado por Price-Mars impone una nueva definición de las culturas populares, desde una perspectiva no etnocéntrica e incipientemente autocrítica del papel del intelectual como mediador cultural. Como Freyre y Ortiz, Price-Mars proviene de la alta burguesía nacional; como éstos, también Price-Mars consolida la antropología nacional como disciplina académica, estableciendo redes de religación con Europa y los Estados Unidos; como éstos, asume posiciones centrales en el campo cultural y político, aunque en su caso se exacerben las contradicciones (menos visibles en los casos de Freyre y Ortiz) entre práctica política y producción intelectual, pues las sucesivas intervenciones de Price-Mars permiten identificarlo como un intelectual orgánico de gobiernos autoritarios, y al mismo tiempo como autor de ensayos progresistas en términos teóricos. ${ }^{17}$

Enunciados en contextos políticos y culturales tanto convergentes como asimétricos, sumergidos en experiencias de crisis con genealogías y pronósticos diversos, los ensayos de Price-Mars, Freyre y Ortiz tienden a interpelar sintéticamente (en términos no-clasistas) a diversos sectores, para configurar de manera incipiente un primer populismo cultural, no

17 Jean Price-Mars (1876-1969) proviene de una familia de la gran burguesía haitiana del norte, y es educado por su padre (negro y protestante) y por su abuela católica, en un ambiente de tolerancia religiosa. Antes de su primer viaje iniciático a Europa (que logra gracias a una beca del Estado haitiano), Price-Mars ya aparece vinculado a intelectuales prevanguardistas, como los nucleados en torno al grupo literario "La Ronde" (del que participa Georges Sylvain entre otros). Estudia Medicina en Francia desde 1899, frecuentando la Sorbonne, el Collège de France y el Musée du Trocadéro, y polemizando personalmente con Gustave Le Bon, figura paradigmática del racialismo europeo. Su perfil como intelectual etnógrafo se define en esa etapa. Al mismo tiempo, su carrera política comienza rápidamente y se extiende por más de cincuenta años, con el ejercicio de diversos cargos diplomáticos en Europa y los Estados Unidos (en donde observa el problema de la discriminación racial y estrecha lazos con otros intelectuales negros). De regreso en Haití, alrededor de 1930 afirma su prestigio como padre intelectual de los vanguardistas haitianos. En ese año se presenta como candidato a Presidente; aunque pierde, ejerce como senador hasta 1932, cuando es expulsado del Senado por la dictadura de Vincent. Las estadías en los países centrales (a causa de la larga carrera diplomática, o de eventuales períodos de exilio) le permiten sortear los límites intelectuales del medio nacional, y acceder a fuentes historiográficas y a teorías etnográficas contemporáneas, elementos que alimentan su investigación (centrada especialmente en el legado del mundo africano). Además, entre los años veinte y treinta Francia funciona para Price-Mars como un espacio privilegiado para el encuentro con numerosos intelectuales de la diáspora africana y del "Harlem Renaissance" norteamericano. De regreso en Haití, en 1941 funda el Institut d'Ethnologie y comparte espacios académicos con el futuro dictador François Duvalier. Su reconocimiento internacional se afirma en los años cincuenta (por ejemplo, cuando en 1956 preside en París el primer congreso de artistas negros). Sólo en el final de su vida protesta contra el uso duvalierista de sus ideas sobre la negritud (puestas por Duvalier al servicio de un nuevo totalitarismo neorracista), convirtiéndose entonces en objeto de persecución política. Al respecto, véase por ejemplo Depestre, René: "Jean Price-Mars y el mito del Orfeo negro", en Price-Mars, René: Así habló el tío, Casa de las Américas, La Habana, 1968. 
exento - como veremos - de componentes legitimistas. ${ }^{18}$ Estos autores adoptan una posición ambigua (central y al mismo tiempo problematizadora) frente a los respectivos campos de poder nacionales, y en especial elaboran discursos rupturistas respecto de los valores de sus clases dirigentes de origen. En ese marco, los tres ensayistas forjan una importante resemantización de las culturas populares, probando hasta qué punto la crisis de representación política se refracta en una profunda crisis de representación discursiva. Los amplios sectores tradicionalmente marginados ya no pueden seguir siendo ignorados, dada su fuerza como mano de obra y/o su capacidad potencial de movilización. De allí la emergencia de un nuevo concepto de lo popular, sesgado aún por contradicciones epistemológicas y estéticas particularmente exasperadas, a tal punto que parece posible leer en ellas, refractadas en el campo cultural, las innumerables ambivalencias y pliegues de las experiencias globales de crisis. En este sentido, los ensayos evidencian el modo en que el discurso latinoamericano gira de manera concéntrica en torno a un nodo crítico que abre una aguda fractura en el orden político, epistemológico y estético, desencadenando el cierre definitivo del siglo XIX.

Ahora bien; consideremos primero comparativamente los ensayos de Freyre y Ortiz, los textos que a nuestro criterio presentan más elementos comunes, tanto desde el punto de vista ideológico como desde la concepción de la escritura. Casa-grande... y el Contrapunteo... contienen una referencia explícita al modo peculiar en que opera en ambas áreas la dinámica del poder, creando "antagonismos en equilibrio". ${ }^{19}$ Así, las tensiones perci-

18 Dada la ambivalencia semántica del término "populismo", cabe aclarar que aquí seguimos la acepción y la perspectiva de análisis desplegada por Moraña en Moraña, Mabel: Literatura y cultura nacional en América Latina (1910-1940), Minneapolis: Institute for the Study of Ideologies and Literatures, 1984. Basándose en las reflexiones teóricas de Ernesto Laclau (en Politics and Ideology in Marxist Theory entre otros textos), Moraña define los populismos latinoamericanos del treinta como discursos ideológicos integrativos que instrumentan una apelación a las masas ante la fragmentación de las estructuras de poder. Sin un contenido político fijo, responden a un momento de crisis del discurso ideológico dominante, buscando indirectamente neutralizar a los sectores dominados. Desde el punto de vista cultural, en la América Latina de los años treinta los populismos asumen la forma de dos principios ideológicos básicos, el nacionalismo y el antiimperialismo, en el marco de los cuales reformulan la tradición cultural hispanoamericana, y redefinen el peso y los componentes de las culturas populares/nacionales.

19 Según la terminología empleada por el propio Freyre, y retomada por Benzaquen de Araújo en el análisis del caso freyreano en - Benzaquen de Araújo, Ricardo: Guerra e paz. Casa-grande e senzala e a obra de Gilberto Freyre nos anos 30, ed. 34, Río de Janeiro, 1994. 
bidas en ese texto clásico de Freyre (entre señores/esclavos, cultura dominante/dominada o latifundio/pequeño cultivo) coinciden con la concepción implícita en el de Ortiz, sobre el contrapunteo "barroco" entre el tabaco y el azúcar, materias primas que operan como vehículo y metáfora de las tensiones de clases, subgrupos y culturas en confrontación. En este sentido, los dos autores parten del mismo presupuesto (en evidencia desde los respectivos títulos) sobre la dinámica de binarismos en diálogo, tendientes a la conformación de una cultura mestiza.

En efecto, aunque Freyre se centra en los intercambios sexuales y culturales suscitados en la intimidad doméstica de las casas-grandes, y Ortiz enfatiza la transculturación generada a partir de la migración simbólica de las materias primas, ambos celebran el mestizaje cultural, erigido en el factor paradigmático desde donde se constituyen las instancias de cohesión que permiten saldar las fracturas sociales, e imaginar una "comunidad nacional".

Pero sobre esta base fuertemente común, los ensayos de Freyre y Ortiz establecen entre sí un "contrapunteo" de diferenciaciones sutiles. Mientras en Casa-grande... la dominación aparece compensada a través de diversas instancias de integración colectiva (por la vía de la sexualidad y de otras prácticas culturales generadoras de cohesión), por oposición en el Contrapunteo... no se visibilizan instancias de comunión, porque las prácticas transculturadas no suponen por sí mismas la cohesión entre polos sociales. Así, en el ensayo cubano la identidad nacional no resulta de ritos de encuentro, sino de la reapropiación múltiple y dinámica, por diversos subgrupos, de algunos materiales comunes, en un escenario variable siempre sesgado por la dominación. Por ende, los modelos de sociedad que entretejen ambos textos resultan diferentes.

Paralelamente, la tensión de clase parece adquirir más peso en el ensayo de Ortiz que en el de Freyre. Ortiz sugiere que no hay una identidad nacional caribeña porque la fragmentación producida por la explotación ha impedido la emergencia de sectores medios y, con ellos, de instancias de mediación que integren los polos sociales enfrentados; en cambio, aunque tampoco Freyre observa la consolidación de grupos medios (al menos hasta fines del siglo XIX), insiste en el modo en que la dinámica de la transculturación genera una cultura nacional integrada a pesar de (y junto con) la polarización social.

En este sentido, Casa-grande... es claramente el punto culminante de una larga tradición discursiva que, desde el siglo XIX, perfila el mito de una 
"democracia racial" sin barreras ni preconceptos. Penetrando profundamente en la sociedad brasileña, ese mito de un universo sincrético y "sin contradicciones" puede permitir ocultar las desigualdades, al exaltar la idea de una convivencia "armónica". Así, reforzando las instancias de cohesión, Freyre adopta una perspectiva integracionista o uniculturalista; en cambio, al reforzar los intercambios culturales pero insistir también en la ausencia de ritos de comunión colectiva (y mantener, por ende, la diferencia entre clases y/o grupos étnicos contrapuestos), Ortiz parece orientarse en favor de una perspectiva pluriculturalista.

Esta diferencia sutil entre las perspectivas de Freyre y Ortiz podría estar respondiendo a tradiciones representacionales heterogéneas, o incluso a procesos de mestizaje desiguales en cada contexto nacional/regional. De hecho, pareciera que las respuestas materiales y simbólicas formuladas ante el mestizaje por la América española en el Caribe, por las Antillas bajo dominio francés y por Brasil hubieran sido divergentes. Al compararlos, el discurso que refuerza el mestizaje, como trazo característico dominante del carácter nacional, parece alcanzar una gravitación mayor en Brasil que en la región antillana. ${ }^{20}$

Tanto Casa-grande como el Contrapunteo... abordan, desde perspectivas homólogas, procesos coloniales similares, sesgados por la fuerte presencia del latifundio de la caña y del sistema esclavista. Al centrarse en las materias primas como el eje privilegiado sobre el que se estructura el proceso histórico, estas perspectivas adquieren un cariz ambiguo, pues por un lado remiten a lo material, a la base económica como determinante; por otro, atraviesan clases y grupos étnicos contrapuestos en el proceso de dominación, reuniéndolos bajo una "comunidad" de producción y de consumo.

Al mismo tiempo, ambos acentúan el análisis de materias primas paradigmáticas de cada economía regional/nacional, como generadoras de "complejos" o "sistemas socioculturales" integradores de múltiples prácticas materiales y simbólicas. ${ }^{21}$

20 Entre otros historiadores contemporáneos, que en términos generales confirman comparaciones clásicas en el ensayismo latinoamericano desde la colonia al s. XIX inclusive, Muranga (1999) advierte que la persecución colonial a las uniones entre "razas" diferentes fue mayor en el Caribe (sobre todo en áreas bajo dominio protestante), que en Brasil.

21 Como resultado de esta preocupación convergente por reconstruir los universos simbólicos ligados a las materias primas que fundamentan esas economías regionales, Ortiz habla del "complejo cultural" del tabaco o de la caña, del mismo modo en que Freyre se refiere, en Nordeste, a una "civilización" del azúcar. 
Ahora bien, al pensar el proceso de expansión de la cultura africana y americana, Ortiz no sólo muestra los mecanismos de resistencia a la colonización, sino que también sugiere una suerte de "colonización invertida" que, por primera vez en la historia antropológica, adquiere connotaciones positivas..$^{22}$ Esta idea ya estaba presente en los inicios de la antropología latinoamericana de entresiglos (así, Nina Rodrigues en Brasil, o el propio Ortiz en su primera etapa, advierten el carácter negativo de la "colonización" de Cuba o Brasil por los negros). La imagen de una "africanización" de la sociedad colonial, al revestir la cultura dominada con los atributos de la cultura dominante, revelaba un grado extremo de etnocentrismo. Rompiendo con esta tradición, y reproduciendo el gesto de Freyre (que exalta la construcción de una cultura mestiza a través de la contaminación positiva de la casa-grande con las prácticas de la senzala), Ortiz celebra la americanización de Europa y la africanización de América a través del mestizaje dinámico de esos "complejos culturales". ${ }^{23}$ Ese gesto se vuelve particularmente provocativo si se lo contrasta con la alarma que, por momentos, manifiestan algunos intelectuales de la vanguardia tanto estética como política en Cuba (Jorge Mañach por ejemplo), negándose a erigir los materiales afroamericanos en "representativos" de la identidad nacional. En efecto, a pesar del peso de la cultura afro en Cuba y del trabajo revalorizador de ésta desplegado contemporáneamente por Fernando Ortiz, la vanguardia cubana aparece más bien desgajada entre el tibio reconocimiento de una cultura primitiva remotamente afro, y una mucho más fuerte recuperación de la vertiente cultural hispánica. ${ }^{24}$

22 El tabaco migra de la cultura indígena a la europea, en un movimiento complejo de "contaminación" múltiple: de las prácticas y valores simbólicos asociados a la cultura indígena, hacia la cultura negra en América, Europa y África, y a las culturas populares y de elite en Europa. Las mutaciones de sentido sufridas por la misma sustancia prueban hasta qué punto para Ortiz ésta opera como base material o escenario sobre el que se despliegan procesos complejos de mestizaje cultural.

23 De hecho, la dinámica cultural es pensada en términos de transculturación no sólo en el ensayo de Ortiz, sino también en el de Freyre, aunque allí no emerja aún la "transculturación" como categoría explícita, acuñada por Ortiz en 1940 y luego retomada por Freyre.

24 El vínculo entre la producción ensayística de Ortiz y la de la vanguardia cubana nucleada en torno al llamado grupo "minorista" (y partícipe de publicaciones significativas como la revista de avance, 1927-1930) resulta particularmente problemático cuando se la analiza desde el punto de vista de la concepción de la cultura popular. Por una parte, Ortiz continuamente cede espacio en las publicaciones y en los ámbitos culturales que dirige para difundir las producciones de la vanguardia estética, evidenciando así un vínculo estrecho de diálogo e identificación recíproca en la construcción convergente de un discurso nacionalista opositor a la ideología oficial. Sin embargo, las miradas de la vanguardia sobre la cultura popular afrocubana resultan todavía en muchos casos elitistas, e incluso sesgadas por residuos del racialismo decimonónico. De hecho, el grupo minorista oscila entre el rescate de las manifestaciones afrocubanas y la reactualización de perspectivas en las que perduran resonancias legitimistas (e incluso racialistas), siendo incapaces de percibir concientemente la perduración de este 
Los procesos económicos y simbólicos ligados al tabaco y al azúcar ponen en evidencia hasta qué punto Ortiz privilegia la focalización de una transculturación "desde abajo" que compensa la dominación "desde arriba". Así, sintomáticamente, en ninguno de los movimientos analizados (ni en el de la caña ni en el del tabaco) la cultura europea adquiere protagonismo colonizador. ${ }^{25}$ De este modo, el Contrapunteo... parece contrabalancear el largo proceso de aculturación, efectivamente más extendido y teóricamente más subrayado por la tradición crítica.

Ambos autores refutan abiertamente la homogeneidad de la cultura, no sólo latinoamericana sino también europea, atravesada por tensiones externas (provenientes del contacto sostenido con África, Oriente y América Latina) y fracturas internas que subrayan su heterogeneidad intrínseca. De este modo, poniendo en crisis los binarismos jerarquizantes que oponen la superioridad de la "pureza europea" a la "hibridez americana", ambos autores destacan su carácter heterogéneo . Así, aunque reproducen explícita o implícitamente algunos binarismos culturales estereotípicos heredados del debate finisecular (como la oposición entre "pragmatismo sajón" y "espiritualismo latino"), también los reformulan al evitar una definición esencialista. Oriente pierde el cariz negativo que generalmente presenta en las perspectivas eurocéntricas "colonialistas" precedentes y contemporáneas y, al mismo tiempo, el mundo ibérico es percibido, desde su "origen", como transculturado: abierto a los procesos de intercambio e integración (y por ende, más apto para intervenir en la gestación de una cultura mestiza).

En ambos ensayistas, la lengua es un escenario privilegiado de esas alquimias sincréticas. Las principales ciudades de Brasil y Cuba, y aun los espacios de interacción rural, surgen como Babeles barrocas en las que indios, esclavos, mulatos y blancos de proveniencias distintas se esfuerzan por sincretizar sus propias lenguas y las lenguas del otro, en un juego dinámico de identificación y diferencia; incluso las lenguas "imperiales" (el

\footnotetext{
y otros residuos heredados del postivismo de entresiglos. En un movimiento ambiguo complementario del anterior, textos como La crisis de la alta cultura en Cuba (1925) de Jorge Mañach identifican cultura nacional y alta cultura, asignándole a la joven elite intelectual el papel mesiánico de guiar la formación de la identidad nacional. Ese elitismo converge con la perduración de varios preconceptos heredados del período anterior (devaluación de la inmigración negra y del mestizaje, sexualización de las jerarquías culturales, reactualización de diversos estereotipos negativos sobre el carácter nacional), poniendo en evidencia así un límite ideológico paradigmático de la vanguardia cubana. Con relación a este aspecto en la obra de Jorge Mañach (y en la revista de avance en su conjunto) véase Manzoni, Celina: Un dilema cubano. Nacionalismo y vanguardia, Casa de las Américas, La Habana, 2001, págs. 207-208.

25 Las prácticas aculturadoras que se mencionan (como la evangelización y la persecución de las culturas populares indígenas y negras) sólo son visibles de hecho en un segundo plano.
} 
español y el portugués) se revelan como contaminadas $a b$ origine por la heterogeneidad. Así, clausurando toda esencialización del lenguaje, ambos autores anticipan las perspectivas posteriores de corrientes como la filología histórica o la sociolingüística, centradas en aprehender transformaciones dinámicas de la lengua en función de un conjunto amplio de variables sociales y culturales. ${ }^{26}$

Por momentos, ambos prolongan una mirada "antropológica" heredera del indianismo romántico y del folklorismo de entresiglos, que vuelve a convertir el ensayo en un "museo" o "galería de curiosidades" extinguidas, aunque ahora, clausurando el reduccionismo de esa tradición decimonónica, se esfuerzan por aprehender al otro, por cargar de densidad semántica esas huellas del pasado.

Los dos ensayistas reconocen el papel clave de las culturas populares en la constitución de las identidades nacionales, privilegiando la gravitación del elemento afro. Pero Ortiz también se esfuerza por recuperar el peso del sustrato indígena (aunque lo sitúa en segundo plano); en cambio, Freyre (influido por la toma de partido frente al debate estético e ideológico contemporáneo) se resiste a valorizar la herencia indígena, para compensar (o incluso refutar) otras versiones contemporáneas de la identidad, como las formuladas por la vanguardia modernista.

Freyre se erige en heredero y superador del ensayismo positivista de entresiglos, y ese pasaje es legible a través de los lazos de afiliación y conflicto que se establecen entre su obra y la de sus "precursores" (especialmente de Nina Rodrigues y Euclides da Cunha). En Ortiz, en cambio, el giro rupturista del etnocentrismo positivista al relativismo de la antropología cultural se revela en el interior de su propia producción. ${ }^{27}$ Ortiz parti-

26 De hecho, los trabajos de Freyre y Ortiz también son pioneros en el plano de la historia de la lengua, sobre todo en la aprehensión de los sustratos afro. Ambos intentan posicionarse en el seno de los largos debates sobre la lengua nacional, que recorren el siglo XIX y llegan hasta las vanguardias inclusive. Reponiendo continuamente la articulación de ciertos términos con los universos simbólicos indígena, afro y europeo, ambos ensayistas ponen en juego (sin jerarquizar) los cruces entre registro culto y oralidades populares europeas, o entre registros europeos y heterogeneidad afro.

En el caso de Ortiz por ejemplo, aun en las obras de su primera etapa (en que adhiere al positivismo racialista), se despliega una concepción dinámica y transculturada de la lengua y la cultura, al fijarse el alcance de los conceptos atendiendo a mutaciones históricas en las que convergen los sustratos heterogéneos y en proceso de contaminación recíproca.

27 El diálogo obsesivo que mantiene Freyre con la tradición precedente para definir el "carácter nacional" (a través de la exaltación de los trazos de cohesión racial y socio-sexual) contrasta con el silencio de Ortiz respecto de un linaje discursivo precedente. Tal vez ese silencio responda a las características del campo intelectual cubano, a la insularidad propia de la cultura caribeña, o incluso al esfuerzo velado de Ortiz por romper con su propio pasado positivista. 
cipa sucesivamente de los universos ideológicos del positivismo y del nuevo paradigma epistemológico de los años cuarenta, evidenciando los lazos de continuidad y ruptura que tienen en los años veinte y treinta su punto de clivaje. ${ }^{28}$

Los dos autores piensan la transculturación a partir de los modelos de intercambio implícitos en las prácticas culturales de los sectores populares, de modo que la reflexión sincrética se apoya en la cultura popular como objeto y como patrón de análisis. En efecto, si Freyre piensa la cohesión a partir del modelo ofrecido por los intercambios sexuales entre esclavas y señores, en el caso de Ortiz es el patrón de la "transmigración de las almas", implícita en varios cultos afrocubanos, el que le permite pensar de manera novedosa la dinámica cultural. ${ }^{29}$

De hecho, podría pensarse que también en Freyre el discurso del mestizaje presenta puntos de contacto significativos con las prácticas religiosas de origen afro. Las operaciones culturales propuestas por ambos autores ofrecen cierta consonancia con respecto a esas religiosidades populares y sincréticas. Tanto la santería afrocubana como el cadombé afrobrasileño suponen una yuxtaposición sintética de identidades migrantes, semejante a la que se despliega en los fenómenos de transculturación; ambos se basan

28 En efecto, entre la primera etapa de Ortiz y el Contrapunteo... se produce un viraje evidente en su concepción de la cultura popular. En Los negros brujos (1906) Ortiz aborda la composición de la marginalidad negra, bajo la influencia de la criminología lombrosiana. Aunque ya el ensayo está atravesado por la preocupación por definir la cultura nacional como afrocubana y mestiza, Ortiz apela sistemáticamente a la categoría de "raza", tendiendo a la criminalización del elemento negro, percibido como una mentalidad "primitiva" inclinada "atávicamente" a la superstición, la lujuria y la violencia. En este sentido existe un paralelo explícito entre las obras del primer Ortiz y las de Nina Rodrigues para el contexto brasileño, a pesar de ciertas diferencias de grado (pues el racialismo extremo del antropólogo bahiano no es comparable con el reformismo más mesurado de Ortiz). Pero para ambos autores el margen y la cultura negros son percibidos como la principal fuerza retrógrada que obtura el progreso; sin embargo, actores y prácticas afro ocupan por primera vez el centro de la escena científica, convertidos en objetos legítimos de conocimiento. Paradójicamente, al registrar sistemáticamente mitos, rituales y creencias negros, los dos autores despliegan una condena "policíaca" de las prácticas populares, y a la vez fundan los estudios afroamericanos, generando las bases sobre las que se apoyarán después la vanguardia estética y el ensayismo "culturalista" (que recuperan, como positividad, esas prácticas populares hasta entonces devaluadas).

29 Ya en los primeros ensayos de Ortiz el margen social y la cultura popular afrocubana (aunque se patologizan y asocian a las clases peligrosas) también se conciben como el espacio privilegiado de las "transfusiones" o "transmigraciones" culturales. En este sentido, seguimos la hipótesis de Díaz Quiñones (1998), que consigue articular lúcidamente la obra de Ortiz explicando los lazos sutiles entre la primera etapa positivista y la siguiente (culturalista), a partir del interés continuo de este autor por el espiritismo kardesiano, lo que le habría permitido cuestionar los límites del positivismo y concebir la "transculturación" como adaptación -en el campo cultural- del concepto de "transmigración" de las almas. 
en la creencia en una relación permanente entre el mundo visible y el invisible, por la mediación de un tercer elemento sincrético. Incluso, sería posible pensar la existencia de un lazo sutil entre la idea de que las culturas afro "colonizan" América y Europa y, en el campo religioso, la creencia en la manifestación de espíritus provenientes de los sectores populares oprimidos: en ambos se valoriza el poder "desde abajo"; en ambos el margen retorna convertido (al menos momentáneamente) en "contra-hegemonía". Quizás ese sincretismo opere en la "estructura profunda" tanto del Contrapunteo... como de Casa-grande..., pues en uno y otro en general se rechazan las oposiciones binarias, y en distintos planos de los análisis se identifica la reunión de los opuestos a través de un factor de mediación. Así, pareciera que en las teorías de Freyre y Ortiz hay "antagonismos en equilibrio" cuyas tensiones no se clausuran, del mismo modo que en el espiritismo brasileño y en la santería afrocubana no hay cuerpo y alma, sino que la yuxtaposición de identidades preservan sus diferencias y dan lugar a un tercer elemento. ${ }^{30}$ Por momentos las imágenes forjadas por ambos autores, sobre la cohesión de etnias y clases sociales heterogéneas, no están lejos de las utopías de reintegración del sujeto y de la sociedad en esas religiones populares, al tiempo que parecen inspirarse (explícita o implícitamente) en esas prácticas como modelos de análisis. ${ }^{31}$ Algo semejante sucede en textos paradigmáticos de la vanguardia brasileña como Macunaíma (1928) de Mário de Andrade, que unos años antes de Casagrande... ya erigen ficcionalmente ciertas prácticas populares (como la "macumba") en patrones de análisis privilegiados para entender temática y formalmente el fenómeno de la transculturación. En efecto, anticipándose a las "ambivalencias en equilibrio" que sesgan en distintos planos los ensayos de Freyre y de Ortiz, travestismos, transmigraciones y metamorfosis de género, raza, clase y/o cultura ocupan un lugar paradigmático en la ficción de Mário porque constituyen modelos identitarios extraídos de las propias

30 Incluso, puede apuntarse como sugestiva cierta correspondencia física que tanto en el espiritismo brasileño como en la teoría de Freyre, el cuerpo se vuelve el escenario privilegiado de las transculturaciones cohesionantes, por la vía de la posesión y de sexualidad respectivamente. Y en ambos se trata de un cuerpo sensual y de un sujeto ambiguo (racional y no racional) sobre el que se produce esa fusión de identidades yuxtapuestas.

31 Por ejemplo, según Aubreé-Laplantine el espiritismo brasileño acentúa fuertemente el carácter conciliador; integra las diferencias sociales, culturales y nacionales, aunque también cree nuevas jerarquías (que reproducen la extrema jerarquización de la sociedad brasileña). No casualmente el espiritismo brasileño participa abiertamente del auge del discurso nacionalista que, en los años treinta, exalta el mestizaje y la cohesión como trazo distintivo de la identidad nacional. Véase Aubrée, MarionFrançois Laplantine: La table, le livre et les esprix. Magies et médiums, J. C, Lattès, Paris, 1990. 
culturas populares y porque operan como metáforas poderosas de esa dinámica cultural peculiarmente contradictoria y mestiza. ${ }^{32}$

Ambiguos, ambos ensayos oscilan entre la ruptura con la tradición discursiva previa en América Latina, que valora negativamente el mestizaje como "factor de atraso", y la confirmación de los lazos que resitúan esos textos en el seno de la tradición. La pregunta por la identidad, y sobre todo cierta remisión a un "origen" mítico "fundacional" (elementos todavía vigentes en ambos ensayos), supone una nueva esencialización de las identidades que contradice el carácter migrante y heterogéneo (contrario a la esencialización y al establecimiento de un origen mítico no-genealógico) postulado para la dinámica cultural.

Además, la preocupación por mostrar instancias de cohesión y coerción en el mundo colonial debilita la "descripción densa" de las culturas populares. En los dos ensayos, la exaltación del mundo de los pobres se empobrece en cuanto a su contenido, traicionando "sin querer" uno de los objetivos principales declarados deliberadamente por los textos.

$\mathrm{Y}$ en ambos, el origen se presenta todavía como un principio de autoridad válido. ${ }^{33}$ Incluso, al idealizar la propia cultura, cada uno coloca el propio mito del mestizaje por encima del mito del otro. Así, repitiendo un ges-

32 Por ejemplo, en el capítulo VII de Macunaíma, el protagonista, desesperado por no conseguir su talismán perdido, acude a una macumba en Río de Janeiro. En ese ritual sincrético, Macunaíma le pide a Exu que haga sufrir a Pietro Pietra (el capitalista que se ha apropiado del talismán); Exu acepta, y la mujer poseída convoca en sí al capitalista, para que Macunaíma la/lo golpee y le ordene verbalmente castigos insólitos que se ejecutan en el cuerpo de la mujer/que es Exu/que es Pietro Pietra (que mágicamente está recibiendo en San Pablo "uma tremendérrima sova"). Por medio de ese juego de cajas chinas, ese cuerpo anómalo de identidades migrantes y múltiples pone en escena el lazo estrecho entre posesión y transculturación. En el clímax mágico de esas yuxtaposiciones absurdas, se superponen las tensiones que fracturan la identidad individual y colectiva (las oposiciones entre tradición y modernidad, masculino y femenino, centro y periferia, inmanencia y trascendencia, aura y desauratización). Así, la ficción parece develar la conexión sutil entre las migraciones espirituales en ese tipo de rituales populares y los procesos dinámicos de mestizaje cultural (en los que también se pone en acto la inestabilidad del sujeto y de la cultura). La convergencia de los polos opuestos subraya la disonancia absurda de los fragmentos heterogéneos e irreductibles con los que se constituyen las identidades sociales, raciales y culturales, en Brasil y en América Latina.

33 Los dos rejerarquizan el escenario nacional y/o regional, tendiendo a la autolegitimación; pero en función de la gran extensión del territorio brasileño frente a la insularidad del Caribe, esta rejerarquización adquiere modulaciones diversas en cada caso: Freyre erige explícitamente el nordeste en origen "verdadero" de la nación (y por lo tanto, en región privilegiada para la configuración de la identidad nacional), mientras que Ortiz concibe la nación como origen de la colonización de América Latina y como centro paradigmático del Caribe. Esa tendencia a la rejerarquización se reproduce en la valoración que cada uno hace de la región del otro. Las Antillas y el nordeste brasileño son concebidos en ambos ensayos como las dos grandes civilizaciones del azúcar en América Latina, con problemas "raciales" y procesos políticos semejantes e interdependientes, pero los autores discuten entre sí para determinar cuál de estas dos "Américas negras" es el modelo "originario" de la otra. 
to colonialista que prolonga el discurso colonial, ambos ensayos reintroducen la misma jerarquización (y con ella, el mismo resabio etnocéntrico) que rechazan al pensar, en términos relativistas, la dinámica cultural.

Si la remisión al origen implica cierta esencialización de las identidades (que las concepciones dinámicas de la cohesión en Freyre, y de la transculturación en Ortiz, compensan sin anular), la urdimbre de un origen acompaña cierta resistencia a la modernización y la adopción de un tono nostálgico respecto del pasado (colonial) perdido. ${ }^{34}$ Sin embargo, si en Freyre parece más fuerte la voluntad por historizar las transformaciones que marcan la clausura de ese orden colonial, esa clausura se hace menos visible en el ensayo de Ortiz: el Contrapunteo... no progresa hacia el progreso, más bien queda preso en una suerte de definición "barroca" sobre el origen barroco de la cultura colonial.

En un punto, ambos ensayos responden a la modernización esforzándose por reinstaurar el "aura" latente en ese pasado perdido: saturan de connotaciones cada detalle de la realidad material, resistiendo la ausencia de sentidos. Desde lugares de enunciación paradójicos, al mismo tiempo críticos y herederos del patriarcalismo conservador, a cuya sombra se han gestado las identidades evocadas por ellos, se erigen en voces privilegiadas para recuperar esos significados "auráticos" de la cultura; a la sombra del ocio aristocrático (y decimonónico) puesto en cuestión, traman largas argumentaciones barrocas "en busca del tiempo perdido". ${ }^{35}$ Resisten la fragmentación y la dispersión de sentidos que proclaman las vanguardias, y en el mismo gesto abren camino y/o consolidan la posición de las vanguardias, al inaugurar nuevas valoraciones de las culturas populares. En un mismo gesto paradójico prolongan y clausuran el siglo XIX.

34 Herederos del ensayismo latinoamericano, ambos autores diseñan textos "híbridos" que buscan conciliar las aspiraciones "científicas" de las ciencias sociales en formación, con residuos de la episteme positivista y de concepciones (metodológicas y genéricas) propias del s. XIX. Apelando a la introducción de elementos del funcionalismo y del materialismo histórico, y a cierta interdisciplinariedad "decimonónica" que resiste la especialización, organizan sus textos como espacios epistemológica y metodológicamente transculturados, incluyendo la filología, la antropología, la sociología, la historiografía o la psicología social como áreas pertinentes para aprehender los procesos de formación de la cultura popular y la identidad nacional.

35 De hecho, no es casual que los dos ensayos conciban implícitamente la cultura y la organización social y política como universos barrocos, o que valoren insistentemente el barroco estético y, al mismo tiempo, desplieguen una mirada saturada de barroquismos. En ese sentido, la literatura modeliza el estilo, la estructura argumental y la ideología de ambos ensayos. En los dos, ese barroquismo conceptual se refracta en la emergencia tanto de una sintaxis oracional como de una estructura argumentativa barrocas, "puestas en acto" de un modo barroco de concebir instancias socioculturales saturadas de tensiones irresueltas. 
Por su parte, la escritura de Price-Mars interviene críticamente en un contexto mucho más exasperado de crisis, forjando indirectamente una respuesta de resistencia cultural. Apuntando a reactivar la conciencia de las elites como guías en la preservación de la autonomía de la nación, ${ }^{36}$ Ainsi parla l'oncle desarticula los fuertes preconceptos heredados del siglo XIX que devalúan la cultura popular de las masas campesinas en Haití, consideradas el foco más africanizado (y por ende, más negativo) de América Latina. Price-Mars diseña así un discurso nacionalista y etnológico para romper con la absurda definición de la nación como "provincia intelectual de Francia" y legitimar por oposición su base afro-haitiana y su carácter sincrético. Con el respaldo de algunos pocos precursores en el Haití de entresiglos (que contrastan con la herencia prolífica recogida abiertamente por Freyre para pensar el campo simbólico de sus precursores nacionales), Price-Mars emprende la refutación sistemática de teorías etnocéntricas y racialistas aún activas en la ideología de la clase dirigente y que, operando como un complejo de inferioridad más intenso que en los otros contextos considerados, obstaculizan la cohesión integradora entre clases. El objetivo inmediato (y sintomáticamente inconfesado por el texto) sería generar un discurso nacionalista capaz de resistir la ocupación norteamericana.

Empeñado en suturar fracturas sociales radicales y en superar una experiencia global de crisis, concentra su reivindicación especialmente en el vudú, convertido en un simbolizador nodal de la cultura popular haitiana por su gravitación paradigmática en los sectores populares. La estigmatización histórica del vudú (reducido a un "fetichismo" primitivo capaz de poner en evidencia la inferioridad racial, o demonizado como un ritual delictivo inclusivo de prácticas antropofágicas) lo convierte en una instancia estratégica para, una vez desarticuladas sus aristas inasimilables, relegitimar desde allí el conjunto de la cultura popular. Contra la herencia miserabilista, Price-Mars concibe el vudú como una religión sincrética del animismo africano y del catolicismo, que habría operado entre los esclavos como la principal instancia de cohesión y de resistencia cultural y política, y que ahora podría erigirse en el principal emblema identitario, integrando discrónica y sincrónicamente campesinado y elite.

Sin embargo, el ensayo no concreta lo que promete: Price-Mars oscila entre el inventario folklorista de fábulas y leyendas populares, que busca saldar un vacío epistemológico que Brasil ya había llenado prolíficamente en entresiglos, con las obras de Sílvio Romero o Nina Rodrigues, y

36 Ese gesto era evidente en su ensayo temprano La vocation de l'elite de 1919. 
la revisión y discusión obsesiva con fuentes europeas (coloniales, positivistas y contemporáneas, de viajeros o de científicos preconceptuosos) que han demonizado el vudú o que, por el contrario, pueden permitirle redimirlo de las acusaciones de primitivismo.

Demorando estratégicamente el prometido abordaje de la religiosidad popular, el ensayo de Price-Mars emprende un largo viaje arqueológico en busca del origen africano de la cultura haitiana. En esa evocación nostálgica del origen reconstruye obsesivamente el "tiempo perdido" de sociedades "evolucionadas" en África, prácticamente desconocidas por Occidente. En este trazo de su escritura se percibe un movimiento paradójico que naufraga a dos aguas: si Price-Mars busca desarmar la estigmatización del continente (y de la raza negra) como el polo opuesto a la civilización, esa arqueología acepta acríticamente que el potencial civilizatorio sólo puede encontrarse en los confines remotos de la historia, y en un espacio imaginario libre de las complejas mutaciones sincréticas derivadas de la experiencia colonial. Como si parodiase "sin querer" las manipulaciones arbitrarias del indianismo romántico, ese cómodo desplazamiento al pasado y al continente puro permite dejar de lado el problema del colonialismo que luego liquidará esas sociedades y dará lugar a complejos procesos de fusión y resistencia. Al mismo tiempo, los antiguos "imperios" africanos se presentan como utopías políticas y babeles armónicas internamente libres de las coerciones de la explotación.

Así, en los pliegues de esa mítica (y farragosa) fundación de un origen subyace, además de una concepción jerarquizadora de la civilización, una rígida esencialización de la cultura que se aleja de la posibilidad de aprehender la compleja dinámica de los mestizajes con el grado de productividad que late en los ensayos de Freyre y Ortiz, así como también en las vanguardias estéticas contemporáneas de Brasil, Cuba y Haití. En ese sentido Ainsi... postula teóricamente el sincretismo, pero lo traiciona en los hechos al concebirlo como una amalgama perfecta y cerrada de materiales puros. El viaje nostálgico y tranquilizador al origen africano obtura la reflexión sobre el papel del mestizaje colonial como fundador de la identidad nacional, privilegiado en cambio en las escrituras de Freyre y Ortiz. Y el movimiento comparativo, que insiste en homologar Haití/África a los modelos occidentales más "legítimos", obtura el análisis de los lazos de la historia y la cultura nacionales con los del resto de América. Esa afiliación simbólica, guiada por una concepción romántico-folklorista de la cultura, resulta sintomática cuando el ensayismo y la vanguardia en América Latina en general insisten en una 
revisión obsesiva del pasado para forjar simbólicamente la unidad continental. Esa perspectiva integradora es evidente - entre otros muchos intelectuales del período- en José Carlos Mariátegui, en Pedro y Max Henríquez Ureña y en Mário de Andrade (amén de los casos aquí considerados de Freyre y Ortiz), e incluso en la propia vanguardia haitiana (nucleada en torno de la figura fundacional del propio Price-Mars).

En esa zona "saudosista" de Ainsi... anidan también otros límites y contradicciones que ponen en crisis esa escritura de crisis. El texto busca la superación del racialismo, pero oscila entre negar y confirmar la categoría de raza, subrayando de este modo la esencialización de la cultura. Esa ambivalencia permitirá la relectura reaccionaria practicada pocos años después por el racialismo negrista de derecha, ${ }^{37}$ volviendo flagrante el fuerte límite ideológico de ese primer discurso de origen, crítico de la crisis y atravesado él mismo por contradicciones críticas capaces de gestar lecturas opuestas, desde el culturalismo y desde el racialismo.

A la vez, Price-Mars confirma la existencia de un lazo estrecho entre medio físico y fuerzas humanas, reactualizando así un tópico clásico del determinismo del siglo XIX. Y en el esfuerzo por revalorizar ese escenario racial y culturalmente devaluado, apela insistentemente a numerosos etnógrafos, arqueólogos e historiadores europeos, evidenciando la extrema ilegitimidad simbólica a la que ha sido confinado el continente negro, pero también la extrema ilegitimidad de la propia palabra que sólo puede sostener su autoridad a partir de la palabra europea. ${ }^{38}$

Y a pesar del esfuerzo por reivindicar la cultura popular nacional, Price-Mars reencuentra la valoración de la "alta cultura" europea como patrón de legitimación. Así, si concibe el créole como transición hacia el francés en la "elevación" cultural de las masas analfabetas, la reivindicación de la cultura popular haitiana emana sobre todo de la operación comparativa que obsesivamente acerca ese universo devaluado a modelos cul-

37 El grupo intelectual Les Griots (liderado entre otros por François Duvalier, que luego se convertirá en dictador de Haití) insiste en el retorno a las raíces afro como origen étnico e histórico claves para entender la realidad haitiana. También la vanguardia estética haitiana (nucleada entre 1927 y 1928 en torno a la Revue Indigène) colabora en la afirmación de las raíces africanas de la cultura nacional, embanderando un retorno simbólico — aunque meramente simbólico — a la Guinea original. Pero aquí no es el vudú, ni la cultura popular afro-haitiana por sí misma, ni el ensayismo folklorista decimonónico, sino el arte de vanguardia el que puede formular un programa cohesionador capaz de consolidar la tradición y de articularla con las expresiones nuevas.

38 Aun así, también enfrenta el eurocentrismo implícito en varias de esas escrituras legítimas, discutiendo calurosamente el concepto de mentalidad "prelógica" en Levy-Bruhl, o la patologización de la posesión religiosa en las teorías psicológicas del positivismo. 
turales (la antigüedad grecolatina, el Egipto milenario o la cultura europea) cuya superioridad no es puesta en discusión. ${ }^{39}$

Finalmente, el texto que cierra el ensayo cierra también retrospectivamente las ambivalencias de significado, y con ellas la potencial riqueza implícita en el resto del libro, en tanto allí se exaspera la operación conservadora que acompaña el esfuerzo bienintencionado de descolonizar lo popular. En principio, Ainsi... se aproxima a Casa-grande... al proyectar la escritura de una antropología de la familia campesina (que desde una concepción amplia de la cultura, debería abordar detalles sobre la alimentación, la lengua, la arquitectura, las creencias religiosas, los lazos comunitarios y los valores). Sin embargo, en una reactualización anacrónica del folklorismo romántico más estereotípico, allí estalla una idealización pastoral del campesinado haitiano que opaca radicalmente la explotación ${ }^{40}$ para sólo exaltar el papel positivo de la magia, supuestamente integradora de los sujetos con la naturaleza, la comunidad y el orden trascendente. En esa asincronía flagrante (que niega todo primitivismo en el mismo momento en que las vanguardias estéticas exaltan con fruición la positividad de lo primitivo) puede entreleerse no sólo la carencia de una sólida tradición folklorista, sino también los rígidos preconceptos de los lectores nacionales que, para admitir la representación de ese universo ilegítimo, obligan a un repliegue del discurso hacia concepciones de la cultura y códigos representacionales que, en otros contextos, ya están muy anquilosados. En este sentido, la asincronía ideológica converge con una escritura formalmente conservadora que, lejos de las exploraciones barrocas (y por ende, más modernas) de Freyre y Ortiz, reproduce rígidamente el modelo estereotípico del ensayo positivista. ${ }^{41}$

39 En este sentido, Price-Mars reactualiza una estrategia que carga con una larga historia en el discurso de reivindicación del continente por intelectuales culturalmente mestizos. Por ejemplo, es el soporte por antonomasia que sostiene, a comienzos del siglo XVII, la reivindicación del incario en los Comentarios Reales del Inca Garcilaso de la Vega.

40 La crítica al oscurecimiento del problema de la explotación en el ensayo de Price-Mars fue formulada por el antropólogo haitiano Rémy Bastien en 1960 ("The Role of the Intellectual in Haitian Plural Society" en Annals of the NewYork Academy of Sciences, $\mathrm{n}^{\circ} 83$ ), dando lugar a una respuesta de autodefensa de parte de Price-Mars. Al respecto, véase Shannon, Magdaline: "Introduction" a PriceMars, Jean. So Spoke the Uncle, Three Continents Press, Quebec, 1973 págs. 21-23.

41 La misma asimetría estético-ideológica se observa en la lectura de la Revue Indigène: allí hay una fuerte ausencia de innovaciones formales (gráficas y literarias), al tiempo que textos paradigmáticos como la "Cronique-Programe" del primer número insisten en la necesidad de conciliar la tradición de l'ideal ancien con quelques pensers nouveaux, contrastando con las manifestaciones de ruptura radical evidentes en la mayoría de las vanguardias latinoamericanas. Del mismo modo, la vanguardia parece converger con Price-Mars en la valoración jerarquizadora de la lengua francesa frente a la cual el créole opera como una simple vía de mediación en la elevación cultural del pueblo. 
En conclusión, al menos teóricamente Freyre, Ortiz y Price-Mars se centran de manera obsesiva en la recuperación de las culturas populares y del mestizaje como instancias paradigmáticas para la definición de la identidad nacional. Sin embargo, los tres autores encuentran dificultades diversas para clausurar definiciones de la cultura netamente decimonónicas. Por momentos, intentan establecer un nuevo vínculo "orgánico" con los sectores populares, erigiéndose en articuladores privilegiados entre la cultura popular y la cultura de elite, al llevar al plano "consciente" elementos implícitos en el "inconsciente" del "pueblo", o exorcizar temores latentes en el inconsciente de las elites.

Tal como se percibe en la comparación, Brasil y Cuba cuentan con prolíficas tradiciones cohesionantes, que bajo la crisis del treinta exigen ser reactivadas y resemantizadas. En contraste, Haití aparece social y culturalmente desgarrado hasta los años treinta inclusive por una suerte de apartheid cultural: frente al vacío de instancias de cohesión, particularmente insostenible en el contexto de una crisis aguda exacerbada por la ocupación norteamericana, el discurso de Price-Mars busca desesperadamente fundar un modelo asimilable de cultura popular/nacional. Mientras Freyre y Ortiz erigen el mestizaje cultural, gestado en la convivencia promiscua de los ingenios coloniales, Price-Mars apela a las prácticas más perseguidas (y más extendidas) de la cultura popular. Sin embargo, la impostación del gesto y los enormes preconceptos con que lidia quedan claros en el silencio del texto frente a los escenarios concretos en que la elite y el pueblo suturaría sus fracturas integrándose bajo la armónica comunión espiritual del rito compartido. El ensayo se detiene en la mera postulación teórica del mismo en símbolo abstracto, en una comunidad imaginada que parece carecer de experiencias de cohesión en el pasado, y que por ende sólo puede integrarse en el espacio utópico del deseo... y del ensayo.

Freyre y Ortiz aprehenden la complejidad de la dinámica cultural gracias a que extraen sus modelos de análisis de las propias prácticas populares (quizás especialmente de las religiosas), pero dan poca densidad semántica a ese universo popular. Price-Mars invierte especularmente ese gesto: se concentra en la práctica vudú, buscando devolverle la complejidad de sentidos aplastada por el etnocentrismo, pero se extravía en el laberinto de los ideologemas con que lidia, cayendo en un esencialismo que le impide explorar la dinámica de los mestizajes culturales y la fuerte gravitación de la dominación material que interviene en dicha dinámica. 
En cierta medida, las tres escrituras ponen en crisis - y hacen crisis ellas mismas- en un mismo punto. Y en este sentido, la crisis de los años treinta se revela como una instancia de ruptura y de continuidad particularmente contradictoria. Oscilando entre residuos formales e ideológicos aún activos, y nuevas "estructuras del sentir" en proceso de formación, el esfuerzo por invertir las connotaciones asignadas al otro teje sus propias trampas: lo popular vuelve a ser moldeado arbitrariamente para forjar una sutura homogeneizadora de la nación (no de la clase), y permanece como un espacio simbólico plagado de representaciones que comienzan a ser deconstruidas sin ser todavía aniquiladas. Así, ninguno de los textos cede el espacio discursivo a la voz del otro ni percibe plenamente al otro fuera del laberinto de imágenes forjadas por la tradición de la elite. La densidad semántica que, con variantes, todavía adquiere el mundo de los pobres sintomatiza la presencia activa de residuos etnocéntricos. Ese hiato, esa fractura que astilla y recompone las imágenes heredadas, atraviesa las escrituras y las epistemologías en crisis procesando así, en el orden simbólico, una experiencia más amplia de crisis — estética, pero también política- de representación. 